\title{
Stress priming in picture naming: An SOA study
}

\author{
Niels O. Schiller, ${ }^{\mathrm{a}, \mathrm{b}, *}$ Paula Fikkert, ${ }^{\mathrm{c}}$ and Clara C. Levelt ${ }^{\mathrm{d}}$ \\ a Department of Neurocognition, Faculty of Psychology, University of Maastricht, P.O. Box 616, 6200 MD Maastricht, The Netherlands \\ ${ }^{\mathrm{b}}$ Max Planck Institute for Psycholinguistics, P.O. Box 310, 6500 AH Nijmegen, The Netherlands \\ ${ }^{\mathrm{c}}$ Department of Dutch, University of Nijmegen, The Netherlands \\ ${ }^{\mathrm{d}}$ Department of Linguistics, University of Leiden, The Netherlands
}

Accepted 3 December 2003

Available online 23 January 2004

\begin{abstract}
This study investigates whether or not the representation of lexical stress information can be primed during speech production. In four experiments, we attempted to prime the stress position of bisyllabic target nouns (picture names) having initial and final stress with auditory prime words having either the same or different stress as the target (e.g., WORtel-MOtor vs. koSTUUM-MOtor; capital letters indicate stressed syllables in prime-target pairs). Furthermore, half of the prime words were semantically related, the other half unrelated. Overall, picture names were not produced faster when the prime word had the same stress as the target than when the prime had different stress, i.e., there was no stress-priming effect in any experiment. This result would not be expected if stress were stored in the lexicon. However, targets with initial stress were responded to faster than final-stress targets. The reason for this effect was neither the quality of the pictures nor frequency of occurrence or voice-key characteristics. We hypothesize here that this stress effect is a genuine encoding effect, i.e., words with stress on the second syllable take longer to be encoded because their stress pattern is irregular with respect to the lexical distribution of bisyllabic stress patterns, even though it can be regular with respect to metrical stress rules in Dutch. The results of the experiments are discussed in the framework of models of phonological encoding. (C) 2003 Elsevier Inc. All rights reserved.
\end{abstract}

Keywords: Speech production; Phonological encoding; Stress priming; Regular vs. irregular stress; Distributional regularities; Dutch

\section{Introduction}

The most prominent theory of phonological encoding to date (Levelt, Roelofs, \& Meyer, 1999; see also Levelt, 2001; Levelt \& Wheeldon, 1994) states that segmental and metrical information is retrieved in parallel during word form encoding in speech production. In that theory, the metrical pattern of a word consists of the number of syllables and the location of the main stress. The metrical pattern of a word is stored in the lexicon only if it deviates from the language-specific default rule for stress assignment; otherwise, stress is not stored but derived by rule. While there is abundant evidence for phonological priming effects in picture naming (see e.g., Schiller, 1998, 2000 for overviews), empirical evidence for stress assignment in psycholinguistics is rare. Roelofs

\footnotetext{
${ }^{*}$ Corresponding author. Fax: +31-43-3884125.

E-mail address: n.schiller@psychology.unimaas.nl (N.O. Schiller).
}

and Meyer (1998) found that participants could only prepare the beginning of a word when they knew both the initial segments AND the metrical frame (e.g., the number of syllables and the location of the lexical stress) of the target. Knowing only the segments OR only the metrical frame of the target did not facilitate naming. For instance, when participants knew that a word started with $m a$ but they did not know whether the target was bisyllabic (e.g., maJOOR 'major'), trisyllabic (e.g., maTErie 'matter'), or quadrisyllabic (e.g., maLAria 'malaria'), there was no preparation effect. Roelofs and Meyer (1998) took their data as evidence that speakers need to have knowledge not only about the segmental structure of words but also about the metrical structure of a to-be-named target in order to prepare overt speech, suggesting that metrical information is-to some extent-retrieved independently of segmental information. However, so far, this is only one study and further evidence is still needed. In a recent study from our own 
laboratory (Schiller, Jansma, Peters, \& Levelt, submitted), we were able to show that the time course of metrical encoding is rightward incremental-just like segmental encoding (Wheeldon \& Levelt, 1995).

Another source of evidence for the encoding of stress are aphasic patients. Nickels and Howard (1999) found that lexical stress location affected word production in a group of seven English patients. All seven patients were significantly worse at repeating bisyllabic words with primary stress on the second syllable relative to words with primary stress on the first syllable. Unstressed initial syllables were often omitted-an observation that Gerken (1994a, 1994b) and Fikkert (1994) also made for young children. Nickels and Howard (1999) suggested that one possible reason for this error pattern might be that initial unstressed syllables are shorter than final unstressed syllables and exhibit increased co-articulation compared to stressed syllables. The extreme case of coarticulating a short syllable would be to omit it. However, their patients rarely produced stress assignment errors, whereas Fikkert (1994) found those errors in Dutch children (fewer stress errors in initially stressed words than in those with final stress).

In a single case study, Miceli and Caramazza (1993) looked at stress assignment errors of an Italian aphasic patient. Italian has - as argued by these authors-lexical stress. Patient CLB often placed stress on the wrong syllable when reading words aloud, e.g., semPLIce instead of SEMplice ('simple'). However, Miceli and Caramazza (1993) showed that CLB was able to assign stress correctly whenever the location of stress was unambiguous on the basis of syllable structure information. This suggested that his sublexical orthography-to-phonology conversion procedures were intact, whereas lexical knowledge (e.g., lexical stress information) about words was damaged. Importantly for our study, Miceli and Caramazza (1993, p. 289) claimed, "that the reading system (and speech production, more generally) contains a non-lexical mechanism for assigning stress to phonological strings on the basis of their syllabic structure [...]." We will come back to this statement in Section 4.

\section{Linguistic accounts of stress in Dutch}

The intricacies of the Dutch stress-system are still under debate. Roughly, two types of accounts have been proposed. In the account of Trommelen and Zonneveld $(1989,1990)$ and Zonneveld, Trommelen, Jessen, Bruce, and Árnason (1999) bisyllabic words receive stress on the initial syllable, except when the final syllable is a socalled super-heavy syllable, i.e., a syllable with a rhyme of the type VVC or VCC (where V stands for vowel and $\mathrm{C}$ stands for consonant). In that case, stress falls on the super-heavy final syllable. According to this theory, words that carry stress on a final syllable, which is not super-heavy, are exceptional (e.g., foREL 'trout' in Dutch). Therefore, the stress patterns of these words are assumed to have stress marked in the lexicon. (Interestingly, trochaic feet are assumed to be assigned from the end of a word towards the beginning of a word in a right-to-left fashion, with main stress assignment to the last foot of the word. However, the words in our experiments only contain one foot.)

In contrast to the above account, Booij (1995) states that the different stress patterns in Dutch can be traced back to the different historical layers in the vocabulary of the language. There is a Germanic pattern, in which stress falls on the initial stressable syllable, a French pattern, with stress on the last syllable with a full vowel, and a Latin pattern, where stress falls on the antepenultimate syllable unless the penultimate syllable is heavy. According to this account, what is stored in the lexicon is, presumably, whether a word belongs to the Germanic, French, or Latin stratum, but not the stress pattern of a word itself. The different strata have different stress rules.

One might derive several predictions from these assumptions. First, it might be assumed that stress patterns that are stored in the lexicon can be primed, but not the ones that are generated by rule. This would predict a priming effect for targets with exceptional stress in Dutch, but not for targets with regular stress. Under a metrical account this would mean that words ending in super-heavy syllables are regular, just like words with initial stress, and should show no priming effect.

Second, one might assume that not only information stored in long-term memory (such as exceptional stress) but also a computational rule such as "stress the first syllable of a word with a full vowel" (Levelt et al., 1999) can be primed. This would predict a priming effect for both regular and exceptional stress words in Dutch. However, there might still be a difference in priming effects between stored information and rules. Third, one might assume - contrary to Levelt's model-that the metrical information of all words is stored, whether regular or exceptional. This would predict priming effects of a similar magnitude for both types of words. There is also a fourth possibility, namely that words might carry markers (for instance, for a specific lexical stratum) that influence the footing procedure in specific ways (Booij, 1995). It is not entirely clear, however, what this would predict for metrical priming. Presumably, words will only receive a lexical stress mark if they are exceptional within a particular stratum. Alternatively, this account may predict that words with the same kind of markers (for instance, for a particular lexical stratum) might potentially prime each other. However, at present, the criteria for grouping words together in a particular stratum are far from clear. 
In psycholinguistic theory (Levelt et al., 1999), the prediction is more straightforward. The default stress pattern in Dutch is initial stress, just like in English (Cutler \& Carter, 1987). A lexico-statistical analysis (Schiller, unpublished) of the Dutch lexicon showed that more than $90 \%$ of the word tokens in Dutch (Levelt \& Schiller, 1998; see also Quené, 1992, 1993) are stressed on the first syllable in a word that can receive stress (schwa-syllables cannot be stressed in Dutch). All words with final stress are considered to be irregular, and have their stress pattern stored in the lexicon. Accordingly, it should in principle be possible to prime final-stress words. In this account distributional patterns, rather than metrical stress rules, determine whether a pattern is regular or irregular.

Our research question in this study was whether (a) the metrical pattern of a word could be primed and (b) whether there was a difference between supposedly stored and supposedly derived metrical patterns.

\subsection{General procedure}

We conducted four experiments in which Dutch native speakers named pictures of everyday objects. Target picture names were all bisyllabic and had initial or final stress. In addition, our participants heard bisyllabic prime words that either had the same or a different stress pattern as the target (see Fig. 1). The primes were displayed via headphones before (Exp. 2), simultaneously with (Exp. 1), or after (Exp.'s 3 and 4) the visual onset of the picture on the screen. Half of the primes were semantically related to the targets, the other half was unrelated. Semantic Relatedness was manipulated for control purposes, i.e., to show that prime words were processed by the participants. Participants were in-
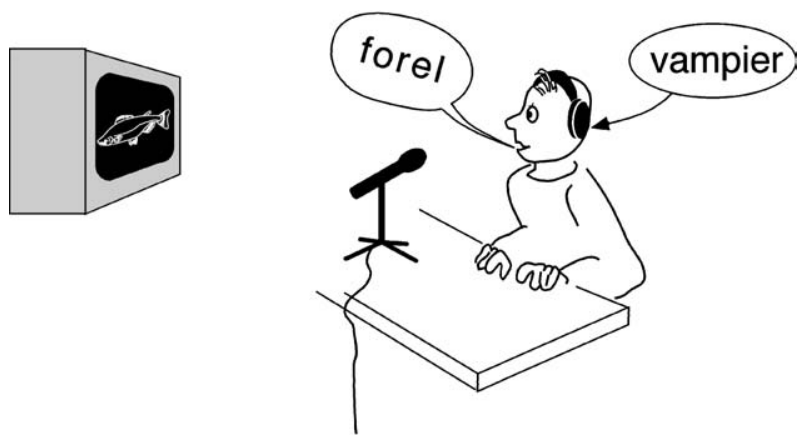

Fig. 1. Set-up of the experiments carried out for this study. On the left, the computer screen is shown, on which the to-be-named visual stimuli (pictures) were shown. The participant sits in front of the screen and a microphone connected to a voice-key is placed between the participant and the screen to record the naming latencies of the pictures. Furthermore, participants wore headphones, on which the auditory prime words were presented. Shown is the target picture of a trout (foREL) paired with the same-stress auditory prime word vampire (vamPIER). structed to name the pictures as fast as possible and ignore the auditory prime words.

\section{Experiment 1: SOA $0 \mathrm{~ms}$}

\subsection{Method}

\subsubsection{Participants}

Nineteen native speakers of Dutch (all undergraduate students at Nijmegen University) took part in this experiment. None of them reported any speech or hearing problems and all had normal or corrected-to-normal vision. Participants were paid for their participation in the experiment.

\subsubsection{Materials}

Thirty-nine black-and-white pictures corresponding to bisyllabic monomorphemic Dutch nouns were selected as targets. Twenty-four picture names had stress on the first syllable, the remaining 15 on the second. Mean frequency of occurrence as determined by CELEX (Baayen, Piepenbrock, \& Gulikers, 1995) was 23.1 per million for targets with initial stress and 18.1 per million for targets with final stress. This difference was not significant $(t(37)<1)$. The pictures were drawn by a professional and taken from the picture database of the Max Planck Institute for Psycholinguistics. In addition, there were 156 bisyllabic auditory prime words (see Appendix A for a complete list of targets and primes). Half of the prime words had initial stress and the other half had final stress. Crossed with the stress manipulation was semantic relatedness, i.e., half of the primes was semantically related to the targets, half of them was unrelated. The prime words in all four conditions had approximately equal frequencies of occurrence, varying on average from 10.4 to 12.6 per one million word forms as determined by CELEX.

\subsubsection{Procedure}

Participants were tested individually in a sound-attenuated booth. They were seated approximately $60 \mathrm{~cm}$ from a computer screen located outside of the booth and visible through a window. Participants wore headphones for the presentation of the auditory prime words. The prime words were spoken by a female voice and recorded on Digital Audio Tape (DAT). Afterwards, the onset and offset of each prime word was determined using the speech analysis package XWAVES. By means of tools developed at the Max Planck Institute for Psycholinguistics, the prime words were spliced from the recording yielding a separate file for each prime word. The Nijmegen Experimental Set-Up (NESU) controlled the trial sequencing. A trial proceeded as follows: First, a fixation point appeared on the screen for $500 \mathrm{~ms}$ followed by a blank screen for $200 \mathrm{~ms}$. Then the target 
picture appeared on the screen and the voice-key was activated. At picture onset, the auditory prime word was also presented. The stimulus onset asynchrony (SOA) between the visual target (picture) and the auditory prime was set to $0 \mathrm{~ms}$ in Experiment 1. The picture remained on the screen for $500 \mathrm{~ms}$ before it disappeared. Participants were instructed to look at the fixation point and name each picture as fast and as accurately as possible ignoring the auditory primes. Naming responses were registered via a Sennheiser microphone that was located in front of them. When no response was registered within $2 \mathrm{~s}$, the next trial started automatically. The inter-trial-interval was $1000 \mathrm{~ms}$. The experimenter who sat outside the booth carefully noted all naming errors and experimental sessions were taped on DAT.

\subsubsection{Design}

The experiment consisted of three phases, i.e., a learning phase, a practice phase, and a testing phase. During the learning phase, pictures were presented on the screen one by one for $2 \mathrm{~s}$. After this period, the corresponding name appeared underneath the picture and both remained in view for another $3 \mathrm{~s}$. This was done to familiarize participants with the pictures and their corresponding names in case alternative names were possible. After a short break the practice phase started, in which participants named each picture once in random order without the presentation of auditory prime words. The purpose of this was to check whether or not participants used the designated picture names and to obtain the naming latencies for the pictures. In case participants did not use the designated name for a picture, the experimenter corrected them. The practice phase was also followed by a break. Then the testing phase started, in which participants also named the target pictures with the designated names but now auditory prime words were also presented at picture onset. Each target was paired with four prime words: Two with the same stress pattern as the target, two with a different stress pattern. In addition, in both the stress-matched and the stress-mismatched category, there was a semantically related prime and a semantically unrelated prime (see also Table 1). Therefore, each picture was presented four times during the testing phase in randomized order each time accompanied by a different prime. Altogether, there were 156 trials (39 pictures $\times 4$ conditions) spread over two blocks with a short break in between.

\subsection{Results}

Targets with initial stress were named faster $(670 \mathrm{~ms})$ than targets with final stress $(739 \mathrm{~ms})$. This $69 \mathrm{~ms}$ effect of Target Stress was significant $\left(F_{1}(1,36)=4.64, M S_{\mathrm{e}}=\right.$ $40917.11, \quad p<.05 ; \quad F_{2}(1,37)=7.19, \quad M S_{\mathrm{e}}=30678.22$, $p<.05)$. The main effect of Semantic Relatedness was also significant $\left(F_{1}(1,36)=16.84, \quad M S_{\mathrm{e}}=1153.41\right.$, $\left.p<.01 ; F_{2}(1,37)=19.40, M S_{\mathrm{e}}=918.59, p<.01\right)$. Semantically related primes yielded longer naming latencies $(704 \mathrm{~ms})$ than semantically unrelated primes (686 ms). Furthermore, Semantic Relatedness interacted with Target Stress $\left(F_{1}(1,36)=8.04, M S_{\mathrm{e}}=1153.41\right.$, $\left.p<.01 ; F_{2}(1,37)=7.88, M S_{\mathrm{e}}=918.59, p<.01\right)$. For targets with initial stress, the semantic interference effect was smaller $(7 \mathrm{~ms})$ than for targets with final stress ( $28 \mathrm{~ms})$. This was especially due to one data point, i.e., the condition in which targets with initial stress were accompanied by prime words with final stress. In this condition, the semantic effect was $5 \mathrm{~ms}$ in the unpredicted direction (i.e., facilitation instead of interference). However, this turned out to be due to semantic aspects of some of the items in this condition (see below). The factor Congruency describing the interaction between target and prime stress did not yield a significant effect itself (both $F$ 's $<1)$, i.e., stress-congruent trials $(692 \mathrm{~ms})$ were on average not produced any faster than stress-incongruent trials $(698 \mathrm{~ms})$. However, Congruency interacted with Target Stress $\left(F_{1}(1,36)=16.41, M S_{\mathrm{e}}=896.15\right.$, $\left.p<.01 ; F_{2}(1,37)=13.99, M S_{\mathrm{e}}=926.45, p<.01\right)$. When targets had initial stress, prime words with initial stress $(660 \mathrm{~ms})$ yielded faster RTs than prime words with final stress $(689 \mathrm{~ms})$. For targets with final stress the results were similar: Primes with initial stress yielded faster RTs (730 ms) than primes with final stress (748 ms; see Fig. 2). The three-way interaction between Target Stress,

Table 1

Example of picture target-prime word pairings

\begin{tabular}{|c|c|c|c|c|}
\hline \multirow[t]{3}{*}{ Target picture } & \multicolumn{4}{|l|}{ Prime words } \\
\hline & \multicolumn{2}{|l|}{ Same stress } & \multicolumn{2}{|l|}{ Different stress } \\
\hline & SEM-related & SEM-unrelated & SEM-related & SEM-unrelated \\
\hline$a$ & maKREEL ('mackerel') & vamPIER ('vampire') & KARper ('carp') & KEtel ('kettle') \\
\hline foREL ('trout' & & & & \\
\hline
\end{tabular}




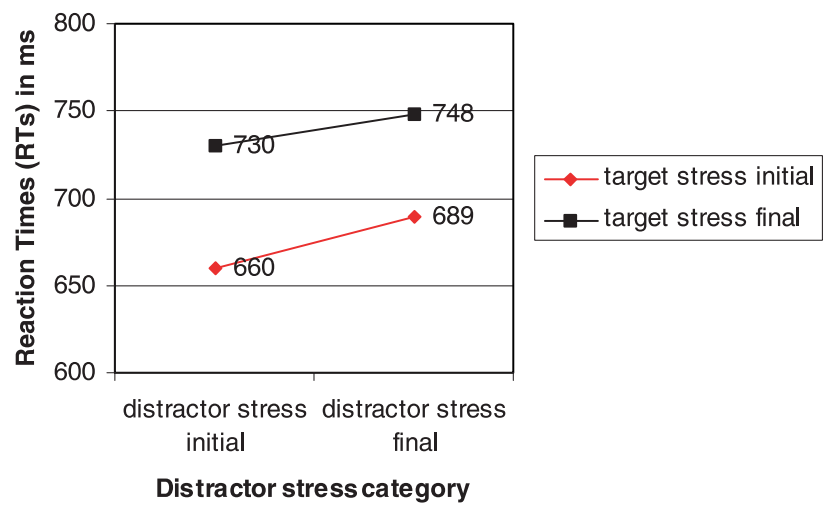

Fig. 2. Results of Experiment $1(\mathrm{SOA}=0 \mathrm{~ms})$.

Congruency, and Semantic Relatedness was not significant (both $F$ 's $<1$ ).

\subsection{Discussion}

The results of Experiment 1 are relatively clear: No stress-priming effect was obtained in this experiment. Although targets with initial stress were produced faster when accompanied with prime words of the same stress than when accompanied by primes of different stress, targets with final stress showed the reversed pattern (see Fig. 2).

Furthermore, targets with initial stress were named faster than targets with final stress. This might be due to several factors: First, picture targets with final stress names might have been more difficult to recognize visually than pictures corresponding to picture names with initial stress. Second, the voice-key threshold might be exceeded more easily and the voice-key might get triggered faster due to acoustic onset characteristics when targets have initial stress than when they have final stress. And last but not least, initial stress might be faster to encode than final stress because it is easier to apply the default rule for stress assignment based on distributional regularities in Dutch than to retrieve the exceptional stress pattern from memory or to compute it by means of metrical stress rules. Even though final stress may be regular on the basis of metrical rules, distributionally speaking it is irregular. Possibly, there are even more explanations, but here we will focus on these three possibilities.

The visual recognizability of the pictures was tested in a control experiment. Twenty-seven Dutch participants, all students from the University of Nijmegen, saw either one of the 39 target pictures of existing objects (e.g., persons, animals, natural and artificial objects) used in the experiment or one of 39 pictures of nonsense objects (taken from Kroll \& Potter, 1984) and were required to press with their preferred hand side as fast and as accurately as possible the YES button of a button box if they thought the picture was denoting an existing object and the $N O$ button otherwise. The trial sequencing was as follows: a fixation point appeared on the screen, followed by the presentation of the picture and the response. Participants visually inspected all the pictures of existing objects and nonsense objects before the object/ non-object decision experiment started. The order of trials was randomized individually for each participant. Only the YES-responses were analyzed. The mean decision latencies for the two stress conditions (first vs. second syllable) were $592 \mathrm{~ms}(S D=127)$ for picture names with first syllable stress (e.g., KAno) and $584 \mathrm{~ms}$ $(S D=136)$ for picture names with second syllable stress (e.g., kaMEEL). The $8 \mathrm{~ms}$ difference between initial and final stress items was not significant $\left(t_{1}(26)=1.06\right.$, $S D=46.69$, n.s.; $\left.t_{2}(38)<1\right)$, which means that pictures whose names had stress on the first or second syllable were recognized equally fast and can therefore not be responsible for the effect in the naming latencies.

Voice-key differences can also be excluded. We carried out a delayed naming control experiment using the exact same pictures as in the main experiment and asked 10 new participants to name them after a fixation point appeared on the screen. There was an interval of at least $1 \mathrm{~s}$ between the onset of the picture and the appearance of the fixation point. Only RTs (measured from fixation point onset) between 200 and $1000 \mathrm{~ms}$ were taken into account for the analysis. It turned out that initial stress targets were named $11 \mathrm{~ms}$ faster than final stress targets; this difference, however, was not reliable by items $\left(t_{1}(9)=3.05, \quad S D=11.10 ; \quad p<.05 ; \quad t_{2}(37)=1.36\right.$, $S D=25.31$, n.s.).

To summarize, picture recognizability and acoustic onset characteristics of the target items used in the experiment are unlikely to be responsible for the naming difference of almost $70 \mathrm{~ms}$. The remaining possibility, i.e., differences in encoding speed between initial and final stress items will be discussed in Section 4.

The Semantic Relatedness effect showed that participants processed the auditory prime words (for an account of semantic interference, see Levelt et al., 1999). Therefore, the question arises why we did not obtain a stress-priming effect. One possibility is that stress is not stored in the lexicon as long as stress can be derived by rule. In our set of target picture names, all but one word (i.e., $f o R E L$ ) were metrically regular, i.e., either stressed on the initial syllable $(n=24)$ or consisting of a superheavy final syllable, which attracted the stress $(n=14)$. Under the assumption that stress is not stored in the lexicon unless it is unpredictable, one would not have predicted a stress-priming effect. Our results are contrary to what Levelt's model would predict, since this model treats all non-initial stress patterns that deviate from the distributionally determined default (i.e., initial stress) as irregular and thus as lexically stored. However, there might also be a second explanation for why we did not obtain a stress-priming effect in Experiment 1, 
namely the SOA between the visual target (picture) and the auditory prime. The prime words might have been presented either too late or too early to yield a stresspriming effect. They could have been presented too late because the transfer of the perceived stress pattern to the production system takes some time. By the time the prime word's stress pattern has been perceived and transferred to the phonological output system, the target picture name has long been encoded, rendering the prime word without any effect. In a second experiment we therefore changed the SOA to $-200 \mathrm{~ms}$.

However, primes could also have been presented too early. According to Indefrey and Levelt (2000), phonological encoding of a target picture name takes place between 275 and $400 \mathrm{~ms}$ after picture onset-for bisyllabic, low frequency picture names as in the current experiment possibly even later. If the auditory prime words transfer information about their stress pattern fast and immediately to the phonological output system and if the decay rate of this type of information is also fast, it might be necessary to present the auditory prime after picture onset rather than before. In a third and fourth experiment we therefore changed the SOA to +150 and $+300 \mathrm{~ms}$, respectively. In these final two experiments we also changed 11 of the auditory primes to make them semantically more related to the targets (see Appendix B for a list of all Target-Prime pairings in Experiments 3 and 4). The reason for this was that in the first two experiments one specific condition, namely the condition in which targets with initial stress were paired with prime words with final stress, yielded a smaller semantic interference effect than the other conditions. With the help of semantic category norms for Dutch (Vonk, 1978) we selected new interfering stimuli for some items. This semantic manipulation of the material worked, since in the third and fourth experiments a semantic interference effect was obtained. However, none of the SOA manipulations had any effect on stress priming: no stress priming was obtained in any of the experiments. We will therefore summarize the results of the remaining experiments in Table 2 below.

In Experiment 2, Target Stress and Semantic Relatedness were again significant (see Table 2). Furthermore, Semantic Relatedness interacted with Target Stress $\left(F_{1}(1,66)=13.59, M S_{\mathrm{e}}=649.24, p<.01\right.$; $\left.F_{2}(1,37)=4.90, M S_{\mathrm{e}}=1102.11, p<.05\right)$. Most importantly, the factor Congruency describing the interaction between target and prime stress was significant by participants $\left(F_{1}(1,66)=6.26, M S_{\mathrm{e}}=565.93, p<.05\right)$ but not by items $\left(F_{2}(1,37)=1.64, M S_{\mathrm{e}}=614.54\right.$, n.s. $)$. On average, stress-congruent trials were produced slightly slower than stress-incongruent trials (see Table 2), contrary to what a stress-priming hypothesis would predict. Again, Congruency interacted (marginally) with Target Stress $\quad\left(F_{1}(1,66)=6.26, \quad M S_{\mathrm{e}}=565.93, \quad p<.05\right.$; $\left.F_{2}(1,37)=3.44, M S_{\mathrm{e}}=614.54, p=.07\right)$. When targets had initial stress, prime words with initial stress yielded slightly faster RTs than prime words with final stress. For targets with final stress, however, the situation was not different: Primes with final stress yielded slower RTs than primes with initial stress (see Fig. 3). The three-way interaction between Target Stress, Congruency, and Semantic Relatedness was not significant (both $F$ 's $<1$ ).

In Experiment 3, Target Stress and Semantic Relatedness were significant, whereas Congruency was not (see Table 2). However, Semantic Relatedness did not interact with Target Stress in this experiment $\left(F_{1}(1,52)=3.65, \quad M S_{\mathrm{e}}=554.83, \quad p=.06 ; \quad F_{2}(1,37)=\right.$ $2.21, M S_{\mathrm{e}}=659.11, \mathrm{n} . \mathrm{s}$.). Although the semantic interference effect was still smaller for targets with initial

Table 2

Overview of the results of all four experiments reported in this study

\begin{tabular}{|c|c|c|c|c|}
\hline & Experiment 1 & Experiment 2 & Experiment 3 & Experiment 4 \\
\hline Number of participants & 19 & 34 & 27 & 20 \\
\hline SOA & 0 & $-200 \mathrm{~ms}$ & $+150 \mathrm{~ms}$ & $+300 \mathrm{~ms}$ \\
\hline Initial Stress & $670 \mathrm{~ms}$ & $695 \mathrm{~ms}$ & $712 \mathrm{~ms}$ & $683 \mathrm{~ms}$ \\
\hline Final Stress & $739 \mathrm{~ms}$ & $749 \mathrm{~ms}$ & $784 \mathrm{~ms}$ & $743 \mathrm{~ms}$ \\
\hline Main effect of Stress & $69 \mathrm{~ms}(*)$ & $54 \mathrm{~ms}(*)$ & $72 \mathrm{~ms}(*)$ & $60 \mathrm{~ms}(*)$ \\
\hline Semantically Related & $704 \mathrm{~ms}$ & $726 \mathrm{~ms}$ & $745 \mathrm{~ms}$ & $706 \mathrm{~ms}$ \\
\hline Semantically Unrelated & $686 \mathrm{~ms}$ & $705 \mathrm{~ms}$ & $732 \mathrm{~ms}$ & $704 \mathrm{~ms}$ \\
\hline Main effect of Semantic Relatedness & $18 \mathrm{~ms}(*)$ & $21 \mathrm{~ms}(*)$ & $13 \mathrm{~ms}(*)$ & $2 \mathrm{~ms}$ (n.s.) \\
\hline Congruent & $692 \mathrm{~ms}$ & $718 \mathrm{~ms}$ & $734 \mathrm{~ms}$ & $704 \mathrm{~ms}$ \\
\hline Incongruent & $698 \mathrm{~ms}$ & $713 \mathrm{~ms}$ & $742 \mathrm{~ms}$ & $705 \mathrm{~ms}$ \\
\hline Main effect of Congruency & $6 \mathrm{~ms}(\mathrm{n} . \mathrm{s})$. & $-5 \mathrm{~ms}$ (n.s.) & $8 \mathrm{~ms}$ (n.s.) & $1 \mathrm{~ms}$ (n.s.) \\
\hline Congruent initial stress & $660 \mathrm{~ms}$ & $694 \mathrm{~ms}$ & $703 \mathrm{~ms}$ & $683 \mathrm{~ms}$ \\
\hline Incongruent initial stress & $689 \mathrm{~ms}$ & $697 \mathrm{~ms}$ & $721 \mathrm{~ms}$ & $683 \mathrm{~ms}$ \\
\hline Congruent final stress & $748 \mathrm{~ms}$ & $756 \mathrm{~ms}$ & $788 \mathrm{~ms}$ & $742 \mathrm{~ms}$ \\
\hline Incongruent final stress & $730 \mathrm{~ms}$ & $741 \mathrm{~ms}$ & $779 \mathrm{~ms}$ & $743 \mathrm{~ms}$ \\
\hline Effect Semantic Relatedness initial stress & $7 \mathrm{~ms}$ & $12 \mathrm{~ms}$ & $9 \mathrm{~ms}$ & $8 \mathrm{~ms}$ \\
\hline Effect Semantic Relatedness final stress & $28 \mathrm{~ms}$ & $35 \mathrm{~ms}$ & $20 \mathrm{~ms}$ & $-6 \mathrm{~ms}$ \\
\hline
\end{tabular}

Note. ${ }^{*} p<.05$ and n.s., not significant. 


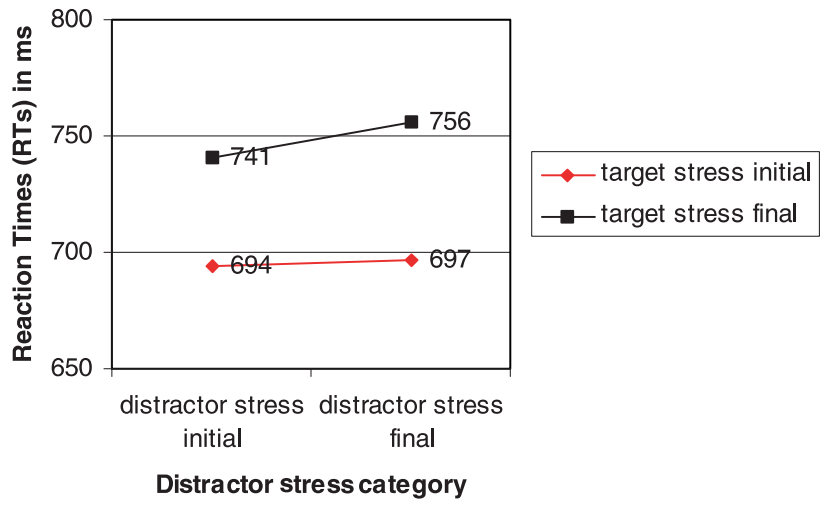

Fig. 3. Results of Experiment $2(\mathrm{SOA}=-200 \mathrm{~ms})$.

stress than for targets with final stress, this difference was not statistically reliable. Also, the one condition in which targets with initial stress were accompanied by prime words with final stress yielded a semantic interference effect. This demonstrates that our manipulation in the materials worked and that the earlier failure to obtain a semantic interference effect was really due to the specific prime-target combinations of the materials.

Again, Congruency interacted with Stress $\left(F_{1}(1,52)=13.34, M S_{\mathrm{e}}=685.06, p<.01 ; F_{2}(1,37)=\right.$ $\left.7.06, M S_{\mathrm{e}}=936.90, p<.05\right)$. When targets had initial stress, prime words with initial stress yielded faster RTs than prime words with final stress. For targets with final stress, the situation was again the same: Primes with final stress yielded slightly slower RTs than primes with initial stress (see Fig. 4). The three-way interaction between Target Stress, Congruency, and Semantic Relatedness was not significant (both $F$ 's $<1$ ).

The effect of Target Stress from the previous experiments is also replicated in Experiment 4, as is the failure of obtaining an effect of Stress (see Fig. 5). However, the main effect of Semantic Relatedness was no longer significant (both $F$ 's $<1$ ). This was, in fact, expected because according to Levelt's model of speech production, conceptual/semantic encoding precedes all other en-

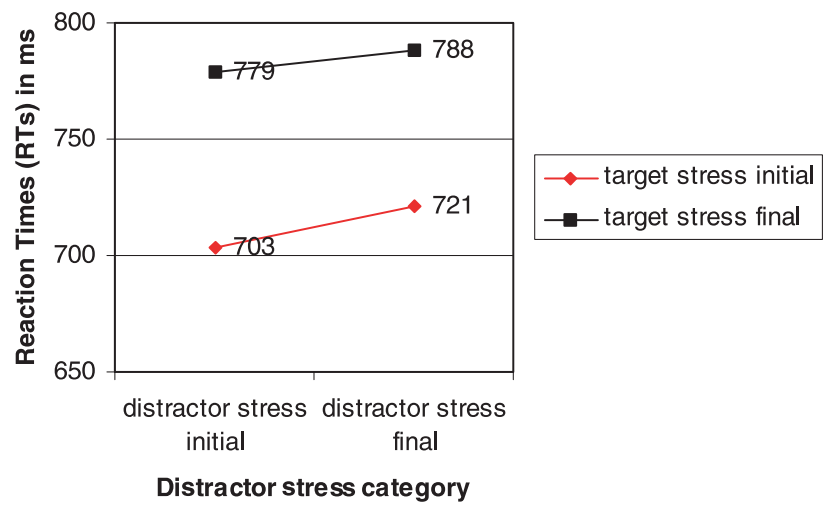

Fig. 4. Results of Experiment $3(\mathrm{SOA}=+150 \mathrm{~ms})$.

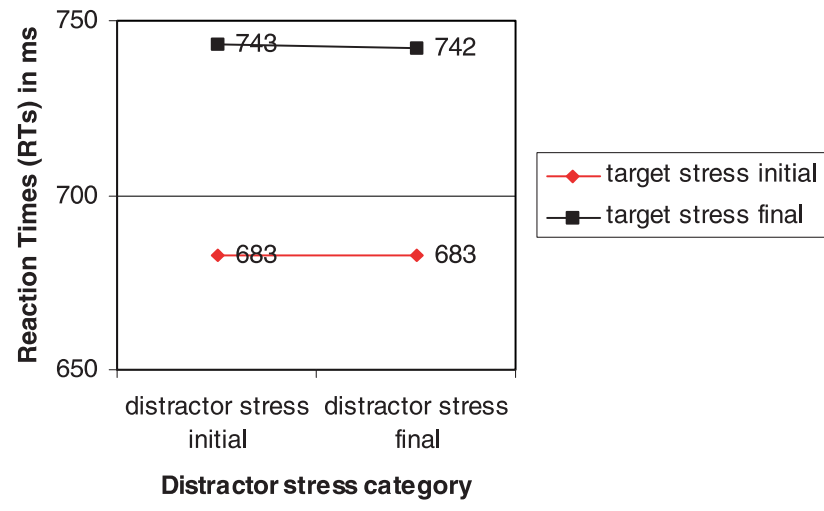

Fig. 5. Results of Experiment $4(\mathrm{SOA}=+300 \mathrm{~ms})$.

coding stages and is supposed to be finished in picture naming after the first few hundred milliseconds (Indefrey \& Levelt, 2000, in press) - depending on word frequency, length, etc. This result replicates also other time course studies on semantic encoding (e.g., Glaser \& Düngelhoff, 1984). None of the other main effects or interactions was significant in Experiment 4.

\section{General discussion}

All four experiments yielded very similar results: Overall, there was no effect of Congruency, i.e., no stress-priming effect. However, we obtained strong and reliable semantic interference effects in three SOAs $(-200,0$, and $+150 \mathrm{~ms})$ demonstrating that the primes were processed and had an effect on the naming latencies. Another interesting effect obtained in all four experiments is that targets with initial stress were named faster than targets with final stress. This effect of Target Stress was neither due to an acoustic target-onset artifact nor did it have something to do with the recognizability of the pictures in the two stress conditions. However, it might be related to the low frequency of the stress pattern in the language, i.e., the distributionally irregular iambic stress pattern in Dutch. This merits further investigation. One possibility for future research would be to block targets according to their stress pattern in an experiment. In very recent work by Meyer, Roelofs, and Levelt (2003) it was shown that length effects in speech production could only be obtained in an experiment with a blocked design, i.e., when all items belonging to one category of items appear in one block. However, this effect could not be obtained in experiments with a mixed design, like ours, possibly due to a strategic response deadline effect.

Concerning the predictions made by different theories as to what type of stress pattern might be sensitive to priming, our present negative results have the following interpretation. The fact that we did not find any significant effect of priming could simply mean that stress is 
not stored in the lexicon, whether it is initial or final. This would undermine psycholinguistic theories in which stress on the final syllable is taken to be irregular, i.e., Levelt et al. (1999). In theories based on linguistic accounts of stress assignment, only words ending in a stressed VV (e.g., buREAU 'desk') or VC (e.g., foREL 'trout') syllable are treated as irregular. Unfortunately, in our experiments the bisyllabic targets with final stress all had - with one exception—super-heavy final syllables. These words have distributionally exceptional but still metrically regular stress according to most accounts (cf. Gussenhoven, 1999; Trommelen \& Zonneveld, 1989, 1990; Zonneveld et al., 1999). Therefore, we would like to propose here that the computation of the language's predominant stress pattern might be faster than the computation of the less frequent stress pattern, which nevertheless can be metrically regular. This would be in agreement with Miceli and Caramazza's (1993) argument that the speech production system has a non- lexical mechanism for stress assignment at its disposal. Until more definite results are obtained, our findings comply best with theories that claim that distributionally exceptional stress patterns are not stored in the lexicon.

\section{Acknowledgments}

Niels O. Schiller is supported by the Royal Dutch Academy of Arts and Sciences (KNAW). Paula Fikkert is supported by the Dutch Organization for Scientific Research (NWO). The authors thank Suzan Kroezen and Mariëlle van Wilgenburg for their assistance in setting up and running the experiments. Thanks for technical assistance go to John Nagengast and Johan Weustink. Last but not least, the authors thank Pim Levelt for his comments on an earlier version of this paper.

\section{Appendix A}

Materials (target pictures and auditory primes) used in Experiments 1 and 2

\begin{tabular}{|c|c|c|c|c|c|}
\hline \multirow[t]{2}{*}{ Targets } & \multirow[t]{2}{*}{ Stress } & \multicolumn{2}{|l|}{ Same stress } & \multicolumn{2}{|c|}{ Different stress } \\
\hline & & $\begin{array}{l}\text { Semantically } \\
\text { related }\end{array}$ & $\begin{array}{l}\text { Semantically } \\
\text { unrelated }\end{array}$ & $\begin{array}{l}\text { Semantically } \\
\text { related }\end{array}$ & $\begin{array}{l}\text { Semantically } \\
\text { unrelated }\end{array}$ \\
\hline \multicolumn{6}{|c|}{ Default stress } \\
\hline auto & 1 & metro & divan & karos & statief \\
\hline motor & 1 & $\operatorname{taxi}$ & wortel & raket & kostuum \\
\hline traktor & 1 & brommer & spijker & wagon & fornuis \\
\hline kano & 1 & gondel & wekker & galei & trofee \\
\hline tijger & 1 & panter & anker & mandril & ventiel \\
\hline kameel & 2 & giraffe & montuur & eland & zegel \\
\hline fazant & 2 & patrijs & pincet & kwartel & hengel \\
\hline konijn & 2 & marmot & augurk & hamster & waaier \\
\hline pinguin & 1 & zebra & harnas & dolfijn & kompas \\
\hline kikker & 1 & vlinder & lepel & libel & servet \\
\hline paling & 1 & wijting & schommel & tonijn & vergiet \\
\hline mossel & 1 & oester & kapper & garnaal & fontein \\
\hline forel & 2 & makreel & vampier & karper & ketel \\
\hline varken & 1 & ezel & masker & kalkoen & tiran \\
\hline tuba & 1 & vleugel & beitel & fagot & gewei \\
\hline cello & 1 & banjo & pinda & hobo & habijt \\
\hline gitaar & 2 & trompet & skelet & trommel & ketting \\
\hline orgel & 1 & bekken & mijter & spinet & brevet \\
\hline viool & 2 & cimbaal & houweel & citer & poedel \\
\hline iglo & 1 & winkel & sleutel & hotel & rivier \\
\hline kasteel & 2 & paleis & gebit & villa & engel \\
\hline tempel & 1 & bunker & hamer & moskee & fossiel \\
\hline toren & 1 & koepel & zadel & kapel & karton \\
\hline molen & 1 & silo & halter & fabriek & orgaan \\
\hline harpoen & 2 & geweer & bureau & degen & pleister \\
\hline pistool & 2 & granaat & ballon & kogel & koffer \\
\hline
\end{tabular}


Appendix A (continued)

\begin{tabular}{|c|c|c|c|c|c|}
\hline \multirow[t]{2}{*}{ Targets } & \multirow[t]{2}{*}{ Stress } & \multicolumn{2}{|l|}{ Same stress } & \multicolumn{2}{|c|}{ Different stress } \\
\hline & & $\begin{array}{l}\text { Semantically } \\
\text { related }\end{array}$ & $\begin{array}{l}\text { Semantically } \\
\text { unrelated }\end{array}$ & $\begin{array}{l}\text { Semantically } \\
\text { related }\end{array}$ & $\begin{array}{l}\text { Semantically } \\
\text { unrelated }\end{array}$ \\
\hline sabel & 1 & knuppel & beker & kanon & boeket \\
\hline meloen & 2 & tomaat & penseel & kiwi & robot \\
\hline appel & 1 & moerbei & ratel & olijf & beha \\
\hline banaan & 2 & pompoen & servies & perzik & tunnel \\
\hline citroen & 2 & rozijn & loket & dadel & borstel \\
\hline aardbei & 1 & mango & vlieger & framboos & vandaal \\
\hline piraat & 2 & bandiet & karaf & rover & kachel \\
\hline jager & 1 & visser & emmer & monteur & ravijn \\
\hline bakker & 1 & dokter & spiegel & agent & gordijn \\
\hline matroos & 2 & sergeant & tapijt & schipper & stempel \\
\hline koning & 1 & joker & wimper & lakei & magneet \\
\hline soldaat & 2 & majoor & matras & monnik & vijver \\
\hline ridder & 1 & schutter & tegel & prinses & sandaal \\
\hline
\end{tabular}

\section{Appendix B}

Materials (target pictures and auditory primes) used in Experiments 3 and 4

\begin{tabular}{|c|c|c|c|c|c|}
\hline \multirow[t]{2}{*}{ Targets } & \multirow[t]{2}{*}{ Stress } & \multicolumn{2}{|l|}{ Same stress } & \multicolumn{2}{|c|}{ Different stress } \\
\hline & & $\begin{array}{l}\text { Semantically } \\
\text { related }\end{array}$ & $\begin{array}{l}\text { Semantically } \\
\text { unrelated }\end{array}$ & $\begin{array}{l}\text { Semantically } \\
\text { related }\end{array}$ & $\begin{array}{l}\text { Semantically } \\
\text { unrelated }\end{array}$ \\
\hline \multicolumn{6}{|c|}{ Default stress } \\
\hline auto & 1 & metro & divan & wagon & statief \\
\hline motor & 1 & $\operatorname{taxi}$ & wortel & raket & kostuum \\
\hline traktor & 1 & brommer & spijker & karos & fornuis \\
\hline kano & 1 & gondel & wekker & galei & trofee \\
\hline tijger & 1 & panter & anker & mandril & ventiel \\
\hline kameel & 2 & giraffe & montuur & eland & zegel \\
\hline fazant & 2 & patrijs & pincet & kwartel & hengel \\
\hline konijn & 2 & marmot & augurk & hamster & waaier \\
\hline pinguin & 1 & zebra & harnas & kalkoen & kompas \\
\hline kikker & 1 & vlinder & lepel & varaan & servet \\
\hline paling & 1 & wijting & schommel & garnaal & vergiet \\
\hline mossel & 1 & oester & kapper & tonijn & fontein \\
\hline forel & 2 & makreel & vampier & karper & ketel \\
\hline varken & 1 & ezel & masker & dolfijn & tiran \\
\hline tuba & 1 & vleugel & beitel & fagot & gewei \\
\hline cello & 1 & banjo & pinda & hobo & habijt \\
\hline gitaar & 2 & trompet & skelet & trommel & ketting \\
\hline orgel & 1 & bekken & mijter & bazuin & brevet \\
\hline viool & 2 & cimbaal & houweel & citer & poedel \\
\hline iglo & 1 & winkel & sleutel & hotel & rivier \\
\hline kasteel & 2 & paleis & gebit & villa & engel \\
\hline tempel & 1 & bunker & hamer & kapel & fossiel \\
\hline toren & 1 & koepel & zadel & moskee & karton \\
\hline molen & 1 & silo & halter & fabriek & orgaan \\
\hline harpoen & 2 & geweer & bureau & degen & pleister \\
\hline pistool & 2 & granaat & ballon & kogel & koffer \\
\hline sabel & 1 & knuppel & beker & kanon & boeket \\
\hline
\end{tabular}


Appendix B (continued)

\begin{tabular}{lllllll}
\hline Targets & Stress & Same stress & & & Different stress & \\
\cline { 5 - 6 } & & $\begin{array}{l}\text { Semantically } \\
\text { related }\end{array}$ & $\begin{array}{l}\text { Semantically } \\
\text { unrelated }\end{array}$ & & $\begin{array}{l}\text { Semantically } \\
\text { related }\end{array}$ & $\begin{array}{l}\text { Semantically } \\
\text { unrelated }\end{array}$ \\
\hline meloen & 2 & tomaat & penseel & & kiwi & robot \\
appel & 1 & moerbei & ratel & & olijf & beha \\
banaan & 2 & pompoen & servies & & perzik & tunnel \\
citroen & 2 & rozijn & dadel & borstel \\
aardbei & 1 & mango & vlieger & & framboos & vandaal \\
piraat & 2 & bandiet & karaf & & rover & kachel \\
jager & 1 & visser & emmer & & monteur & ravijn \\
bakker & 1 & dokter & spiegel & & agent & gordijn \\
matroos & 2 & sergeant & tapijt & & schipper & stempel \\
koning & 1 & joker & wimper & & lakei & magneet \\
soldaat & 2 & majoor & matras & & monnik & vijver \\
ridder & 1 & schutter & tegel & baron & sandaal \\
\hline
\end{tabular}

\section{References}

Baayen, R. H., Piepenbrock, R., \& Gulikers, L. (1995). The CELEX lexical database (CD-ROM). Philadelphia: Linguistic Data Consortium, University of Pennsylvania.

Booij, G. (1995). The phonology of Dutch. Oxford: Clarendon Press.

Cutler, A., \& Carter, D. M. (1987). The predominance of strong initial syllables in the English vocabulary. Computer Speech and Language, 2, 133-142.

Fikkert, P. (1994). On the acquisition of prosodic structure. Doctoral dissertation University of Leiden, HIL Dissertations 6. The Hague: Holland Academic Graphics.

Gerken, L. (1994a). A metrical template account of children's weak syllable omissions from multisyllabic words. Journal of Child Language, 21, 565-584.

Gerken, L. (1994b). Young children's representation of prosodic phonology: Evidence from English-speakers' weak syllable productions. Journal of Memory and Language, 33, 19-38.

Glaser, W. R., \& Düngelhoff, F.-J. (1984). The time course of pictureword interference. Journal of Experimental Psychology: Human Perception and Performance, 10, 640-654.

Gussenhoven, C. (1999). Vowel duration, syllable quantity and stress in Dutch. Unpublished manuscript. University of Nijmegen.

Indefrey, P., \& Levelt, W. J. M. (2000). The neural correlates of language production. In M. Gazzaniga (Ed.), The new cognitive neurosciences (pp. 845-865). Cambridge, MA: MIT Press.

Indefrey, P., \& Levelt, W. J. M. (in press). The spatial and temporal signatures of word production components. Cognition.

Kroll, J. F., \& Potter, M. C. (1984). Recognizing words, pictures, and concepts: A comparison of lexical, object, and reality decisions. Journal of Verbal Learning and Verbal Behavior, 23, 39-66.

Levelt, W. J. M. (2001). Spoken word production: A theory of lexical access. Proceedings of the National Academy of Sciences of the United States of America, 98, 13464-13471.

Levelt, W. J. M., Roelofs, A., \& Meyer, A. S. (1999). A theory of lexical access in speech production. Behavioral and Brain Sciences, $22,1-75$.

Levelt, W. J. M., \& Schiller, N. O. (1998). Is the syllable frame stored? Behavioral and Brain Sciences, 21, 520.

Levelt, W. J. M., \& Wheeldon, L. (1994). Do speakers have access to a mental syllabary? Cognition, 50, 239-269.
Meyer, A. S., Roelofs, A., \& Levelt, W. J. M. (2003). Word length effects in object naming: The role of a response criterion. Journal of Memory and Language, 48, 131-147.

Miceli, G., \& Caramazza, A. (1993). The assignment of word stress in oral reading: Evidence from a case of acquired dyslexia. Cognitive Neuropsychology, 10, 273-296.

Nickels, L., \& Howard, D. (1999). Effects of lexical stress on aphasic word production. Clinical Linguistics and Phonetics, 13, 269-294.

Quené, H. (1992). Integration of acoustic-phonetic cues in word segmentation. In M. E. H. Schouten (Ed.), The auditory processing of speech: From sounds to words (pp. 349-356). Berlin: Mouton de Gruyter.

Quené, H. (1993). Segment durations and accent as cues to word segmentation in Dutch. Journal of the Acoustical Society of America, 94, 2027-2035.

Roelofs, A., \& Meyer, A. S. (1998). Metrical structure in planning the production of spoken words. Journal of Experimental Psychology: Learning, Memory, and Cognition, 24, 922-939.

Schiller, N. O. (1998). The effect of visually masked syllable primes on the naming latencies of words and pictures. Journal of Memory and Language, 39, 484-507.

Schiller, N. O. (2000). Single word production in English: The role of subsyllabic units during phonological encoding. Journal of Experimental Psychology: Learning, Memory, and Cognition, 26, 512-528.

Schiller, N. O., Jansma, B. M., Peters, J., \& Levelt, W. J. M. (submitted). Monitoring metrical stress in polysyllabic words. Language and Cognitive Processes.

Trommelen, M., \& Zonneveld, W. (1989). Klemtoon en metrische fonologie [Stress and metrical phonology]. Muiderberg: Coutinho.

Trommelen, M., \& Zonneveld, W. (1990). Stress in English and Dutch: A comparison. Dutch Working Papers in English Language and Linguistics, 17.

Vonk, W. (1978). Categorienormen voor woorden in 34 categoriën ['Category norms for words in 34 categories']. Heymans Bulletins HB 78-373, Rijks Universiteit Groningen.

Wheeldon, L., \& Levelt, W. J. M. (1995). Monitoring the time course of phonological encoding. Journal of Memory and Language, 34, 311-334.

Zonneveld, W., Trommelen, M., Jessen, M., Bruce, G., \& Árnason, K. (1999). Word-stress in West-Germanic and North-Germanic languages. In H. van der Hulst (Ed.), Word prosodic systems (pp. 477603). Berlin: Mouton. 